\title{
Does the type of pancreatic anastomosis following pancreaticoduodenectomy affect the surgical outcome? A randomized, prospective trial
}

\author{
Ahmed Nafei, MD; Ali Mohamed El Anwar, MD; Hisham Adel, MD; \\ Anas Meshael, MD; Alaa Abdallah, $M D$
}

Department of General Surgery, Ain Shams University, Cairo, Egypt.

\begin{abstract}
Objective: To compare the results of pancreaticogastrostomy versus pancreaticojejunostomy following pancreaticoduodenectomy in a prospective randomized trial.

Background: Pancreatic leak and fistula are the most leading cause of morbidity and mortality after pancreaticoduodenectomy. Many reports have suggested that pancreaticogastrostomy is less likely than pancreaticojejunostomy to be associated with pancreatic leak. However, other trials have reported no difference inbetween both groups.

Methods: All patients undergoing pancreaticoduodenectomy in Ain Shams Hospitals between May 2004 and June 2009 were randomized to one of two groups in the reconstructive phase of the operation, either pancreaticogastrostomy or pancreaticojejunostomy group .

Main outcome measures: Mortality and morbidity following pancreaticogastrostomy and pancreaticojejunostomy, especially pancreatic anastomotic leakage.

Results: 33 patients underwent pancreaticoduodenectomy. Of these 18 had pancreaticogastrostomy and 15 had pancreaticojejunostomy. There were 20 males and 13 females with a mean age of 57.4 years. There were no significant differences between groups on comparison of preoperative data, patient's characteristics and operative parameters except that the operative time and blood transfusion were insignificantly higher in PG group. Postoperatively, the mortality and morbidity rates did not differ between the PG and PJ group. The rate of pancreatic leak was not significantly different between both groups. However, the overall complications were higher in pancreaticojejunostomy. Pancreatic leak was found to be higher in patients with soft pancreas, small pancreatic duct, and to a lesser extent in elderly patients, long operative time and higher intraoperative blood loss.

Conclusion: Pancreaticogastrostomy is safer than pancreaticojejunostomy after pancreaticoduodenectomy. Some important factors such as surgeon's experience, pancreatic texture, size of the pancreatic duct and to a lesser extent; patient's age, operative time and intraoperative blood loss play a contributory role in pancreatic anastomotic leakage.

Key words: Pancreaticoduodenectomy, pancreaticogastrostomy, pancreaticojejunostomy.
\end{abstract}

\section{Introduction:}

Pancreaticoduodenectomy (PD) is technically a demanding procedure as the reconstructive phase in PD has always been a major problem. At experienced high volume centers, there is considerable post-operative morbidity around $30-50 \% .1,2$

At present the most significant cause of morbidity and mortality after PD is the development of pancreatic leak and consequent fistula, and of up to $20 \%$ are reported from centers specializing in pancreatic surgery. ${ }^{2,3}$

Pancreaticojejunostomy (PJ) and pancreaticogastrostomy (PG) are the most common used reconstructive techniques in the management of pancreatic cuff after PD. Both techniques are open to debate for some authors have presented to a very low leak rate with $\mathrm{PJ},{ }^{4}$ while others have shown that PG is safer than PJ and is associated with lower incidence 
of mortality and morbidity. 5

We conducted this study to compare PJ with PG with regard to safety of the pancreatic anastomosis.

\section{Patients and methods: Study design:}

This is a prospective randomized study that was conducted on all patients who underwent pancreaticoduodenectomy at Ain Shams Hospitals from May 2004 to June 2009. Enrolled patients were assigned to one of two groups according to the type of management of the pancreatic remnant, whether pancreaticogastrostomy (PG) or pancreaticojejunostomy (PJ) group.

\section{Data collection:}

Enrolled patients were subjected to detailed medical history, thorough physical examination and preoperative laboratory investigations.

Diagnostic imaging workup included abdominal ultrasonography (US) and spiral computed scan (CT). Preoperative endoscopic retrograde cholangiopancreatography (ERCP) and biliary stenting were performed if total bilirubin exceeded $8 \mathrm{mg} / \mathrm{dl}$ prior to surgery.

All patients were given prophylactic perioperative $3 \mathrm{rd}$ generation cephalosporins and prophylaxis for deep venous thrombosis (DVT) for 7 days. Prophylactic somatostatin analogue was not used in this study.

After obtaining an informed written consent, the patients were randomized to either PG or PJ group. Operative data were collected and included operative details, estimated blood loss, intraoperative blood transfusion, pancreas texture, size of pancreatic duct, and operative time.

Post-operative parameters included time to removal of nasogastric tube, time to resumption of regular diet, time to removal of operative drains, postoperative stay and histopathologic diagnosis, post-operative extra-abdominal complications such as cardiopulmonary, DVT, and cerebrovascular complications, and abdominal complications such as pancreatic leak, pancreatic fistula and consequent septicemia, delayed gastric emptying, wound infection, hemorrhage, intra-abdominal fluid collection and abscess, acute pancreatitis, gastro-enteric/ biliary leak or fistula, percutaneous radiological intervention and relaparotomy rate, and finally date and cause of death.

\section{Study endpoint and objectives:}

The study endpoint was to compare the two groups of treatment on the base of the development of pancreatic leak and fistula with their subsequent complications.

\section{Surgical techniques:}

Pancreaticoduodenectomy was performed as a partial pancreatectomy with either conventional PD (partial pancreatectomy with distal gastrectomy) or with pylorus preserving PD. At the completion of the PD, the pancreas texture was assessed and the diameter of the pancreatic duct was measured. All pancreatic anastomosis were performed in two layers: 30 polyglactin for the inner layer and 3-0 silk for the outer layer. Duct-to-mucosa technique was done. Stent with internal drainage was inserted across the anastomosis. Tube gastrostomy and feeding jejunostomy were not done.

Pancreatic anastomosis was performed first, followed by end to side hepaticojejunostomy and finally end to side duodenojejunostomy or gastrojejunostomy.

PJ Figure(1) was performed in end to side fashion. Jejunum was brought through a window in the right transverse mesocolon, with PJ being performed to the most proximal jejunum. A posterior outer layer of interrupted $3 / 0$ silk sutures was placed between the posterior pancreatic capsule and the seromuscular layer of the jejunum. A small full-thickness jejunostomy is created using electrocautery, in line with the pancreatic duct. The inner layer consisted of the pancreatic duct and mucosa of the jejunum, interrupted sutures for duct-to-duct were performed using $3 / 0$ polyglactin sutures. Finally, an anterior outer layer of interrupted 3/0 silk sutures was placed in a manner similar to the outer posterior layer.

In PG Figure(2,3), anastomosis was carried out on the posterior wall of the stomach midway between the greater and lesser curvature, at least $5 \mathrm{~cm}$ away from the cut end of the 
stomach. Duct-to-mucosa technique was done as in PJ.

A suction drain was introduced through left-sided abdominal stab incision and placed in the vicinity of the pancreatic anastomosis.
Another suction drain was introduced through right- sided abdominal stab incision and placed in the vicinity of the hepaticojejunostomy.

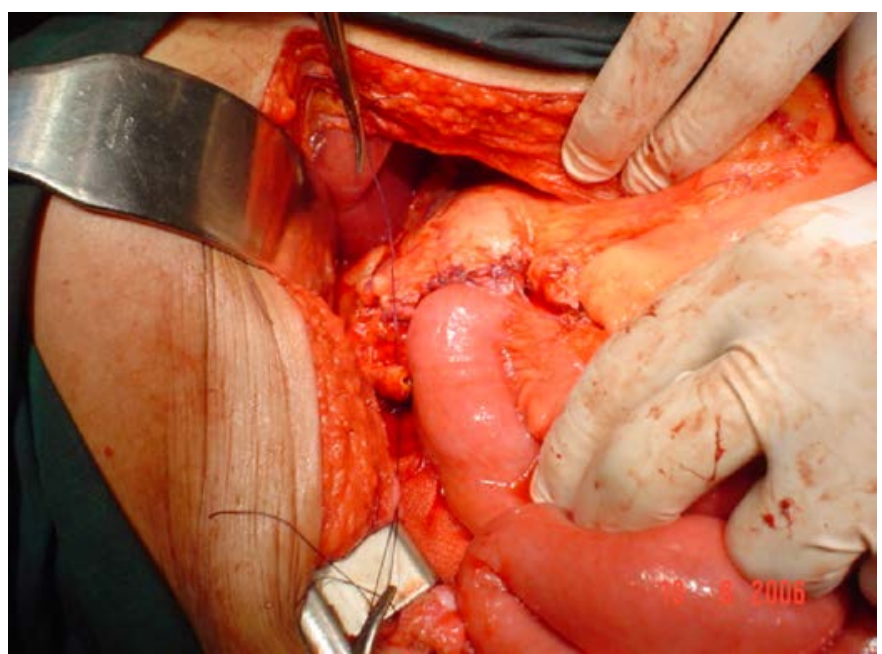

Figure (1): Pancreaticojejunostomy.

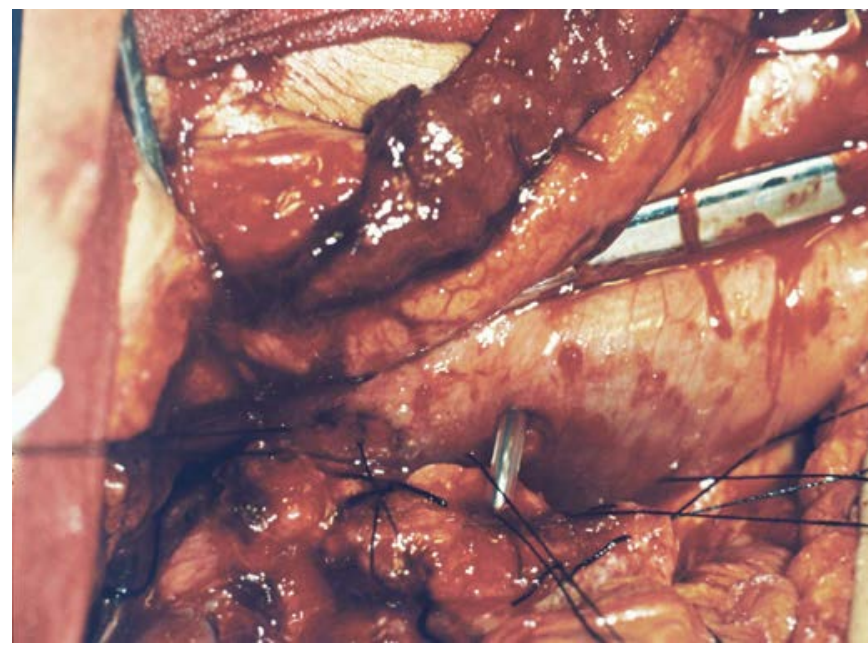

Figure (2): Duct to mucosa pancreaticogastrostomy with stent insertion.

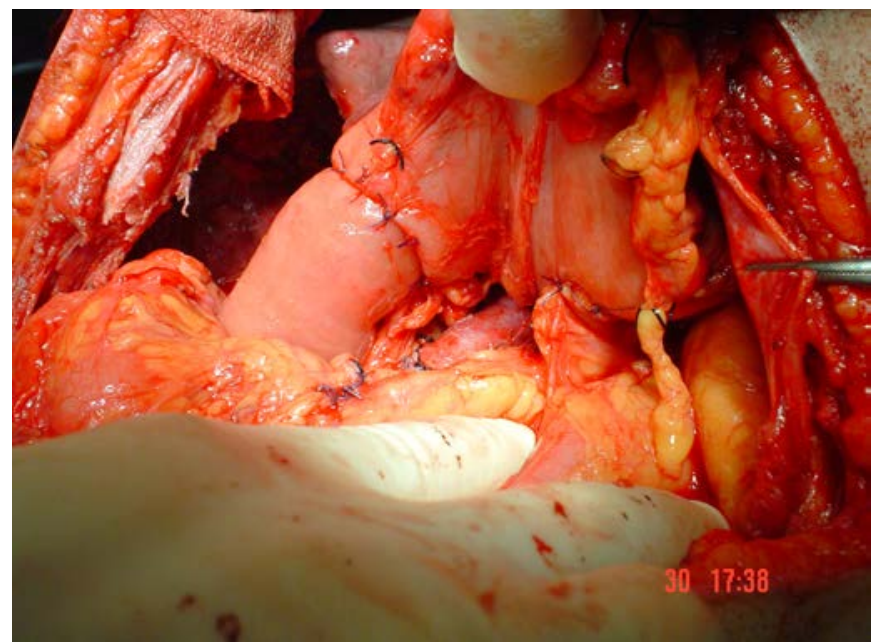

Figure (3): Pancreaticogastrostomy at right side, gastrojejunostomy at left side. 


\section{Postoperative management:}

During the postoperative period, patients received prophylactic 3 rd generation cephalosporins, antithrombotic, and peptic ulcer prophylaxis. Prophylactic somatostatin analogue was not used in this study. Nasogastric tube was left for at least two days and was removed when the output was less than 100 $\mathrm{ml}$ per day. Oral fluid was given to the patient on the 5th postoperative day after intestinal sound auscultation, and then feeding was graduated as tolerated. Delayed gastric emptying was defined as a need for nasogastric suction for more than 10 days after PD.

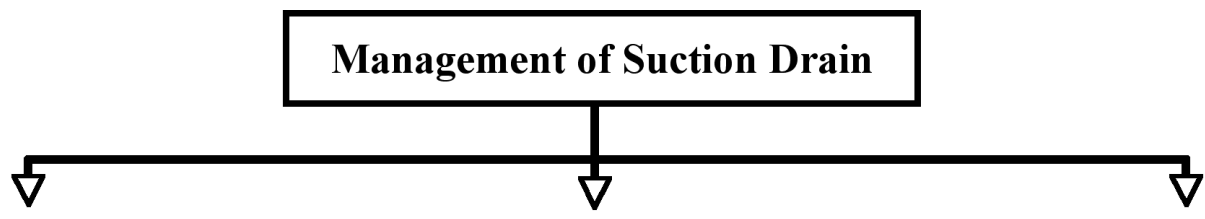

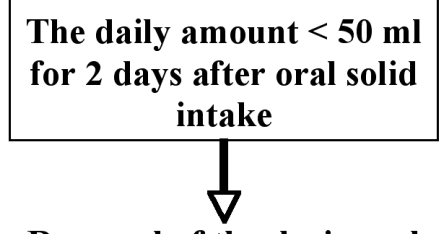

Removal of the drain and patient was discharged for follow up after one week
Daily drain amount $<50 \mathrm{ml}$ but the patient's general condition and laboratory values were not satisfactory

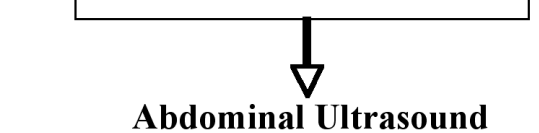

Daily drain amount starting from the $3^{\text {rd }}$ postoperative day $>50 \mathrm{ml}$ and drain amylase $>3$ times serum amylase

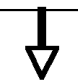

Drain was kept and patient was observed

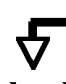

Abdominal collection<smiles>C[Te]</smiles>

- Percutaneous drainage

- Observation

- Follow up

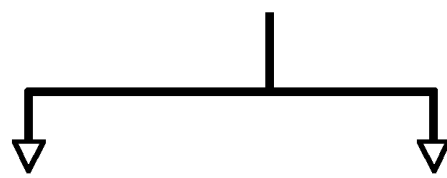

- Patient is improved Patient was deteriorating

- No recollection<smiles>C[Te]</smiles>

Removal of the drain and patient was discharged for follow up after one week or recollection

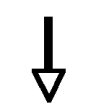

Exploration

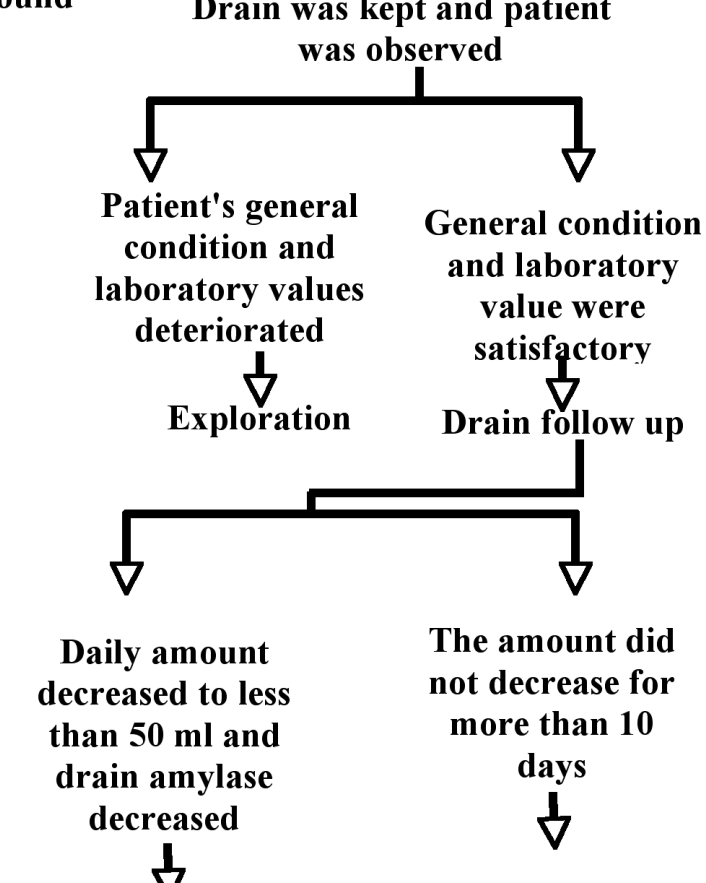

Drains were removed

An algorithm showing management of suction drain in our study.

Patients with diagnosed pancreatic fistula were managed conservatively by somatostatin analogue, 3rd generation cephalosporins, metronidazole, prophylactic proton pump inhibitors, total parentral nutrition (TPN) and prophylaxis against deep venous thrombosis (DVT). These patients were strictly observed in the hospital until the fistula closed spontaneously and the date of closure was registered. In complicated fistula, such as intraperitoneal collection, abscess, septicemia or intraperitoneal hemorrhage, the corresponding suitable line of management was performed, such as percutaneous drainage, or relaparotomy. 


\section{Results:}

Thirty three patients underwent PD between May 2004 and June 2009. Of these 18 had PG $(54.5 \%)$ and $15(45.5 \%)$ had PJ. There were 20 males $(60.5 \%)$ and 13 females $(39.5 \%)$ with a mean age of 57.4 years. Table(1) shows the patient characteristics and preoperative variables. No significant differences were observed between the PG and PJ groups on comparison of patient's characteristics and preoperative parameters. The pylorus preserving PD was performed in 7 patients $(21.5 \%)$ whereas the classic PD was performed in 26 patients $(78.5) \%$.

Table(2) shows the intraoperative variables in both groups. It reflects no significant differences between the PG and PJ groups on comparison of intraoperative parameters. Operative time and blood transfusion were insignificantly higher in PG group.
Carcinoma of the head of pancreas was the most common histopathologic diagnosis accounting for $45.5 \%$ of cases as shown in Table(3).

The overall incidence of pancreatic leak was $8 / 33(24 \%)$, 4 belonging to PG group (22\%), and 4 belonging to PJ group (26.5\%). Abdominal US revealed abdominal collection in 3 of them, one from PG group and two from $\mathrm{PJ}$ group. Percutaneous drainage was done in these patients. However, recollection and deterioration of the general condition occurred in two of them, one from each group, whilst the 3rd patient developed pancreatic fistula. Urgent relaparotomy was planned for these two patients with abdominal recollection. However, one of them died before exploration and the other died three days after exploration and drainage. These two patients died from septicemia and multi-organ failure. 
Table (1): Patient's characteristics and preoperative parameters.

\begin{tabular}{|c|c|c|}
\hline $\begin{array}{l}\text { Age (years) } \\
\text { Mean } \\
\text { Range }\end{array}$ & $\begin{array}{l}58.3 \\
33-69\end{array}$ & $\begin{array}{l}56.9 \\
37-67\end{array}$ \\
\hline $\begin{array}{l}\text { Sex } \\
\quad \text { Male } \\
\text { Female }\end{array}$ & $\begin{array}{c}10 \\
8\end{array}$ & $\begin{array}{l}10 \\
5\end{array}$ \\
\hline $\begin{array}{l}\text { Preoperative history } \\
\text { Jaundice } \\
\text { Weight loss } \\
\text { Abdominal pain } \\
\text { Pruritis } \\
\text { Previous upper abdominal surgery } \\
\text { Hypertension } \\
\text { Coronary artery disease } \\
\text { Diabetes mellitus } \\
\text { Bronchial Asthma } \\
\text { Peptic ulcer } \\
\text { Smoking } \\
\text { Alcohol intake }\end{array}$ & $\begin{array}{l}10 \\
6 \\
5 \\
4 \\
1 \\
6 \\
1 \\
5 \\
1 \\
1 \\
10 \\
2\end{array}$ & $\begin{array}{l}9 \\
6 \\
4 \\
4 \\
2 \\
4 \\
1 \\
3 \\
0 \\
1 \\
7 \\
1\end{array}$ \\
\hline $\begin{array}{l}\text { American Society of } \\
\text { Anesthesiologists grade (ASA) } \\
\text { I } \\
\text { II } \\
\text { III }\end{array}$ & $\begin{array}{l}6 \\
11 \\
1\end{array}$ & $\begin{array}{l}5 \\
9 \\
1\end{array}$ \\
\hline $\begin{array}{l}\text { Preoperative Laboratory } \\
\text { Values (average) } \\
\text { Hematocrit }(\%) \\
\text { While blood cell count } \\
(10 \text { cell/m3) } \\
\text { Creatinine }(\mathrm{mg} / \mathrm{dl}) \\
\text { Total bilirubin }(\mathrm{mg} / \mathrm{dl}) \\
\text { Direct bilirubin }(\mathrm{mg} / \mathrm{dl}) \\
\text { Alkaline phosphate } \\
\text { Albumin }(\mathrm{g} / \mathrm{dl}) \\
\text { ALT } \\
\text { Fasting blood sugar } \\
\text { Amylase }\end{array}$ & $\begin{array}{l}37.2 \\
8.9 \\
1.0 \\
6.9 \\
4.3 \\
412 \\
3.6 \\
41 \\
132 \\
128\end{array}$ & $\begin{array}{l}35.7 \\
\\
9.4 \\
1.1 \\
6.1 \\
4.1 \\
399 \\
3.5 \\
38 \\
118 \\
137\end{array}$ \\
\hline $\begin{array}{l}\text { Preoperative ERCP and stenting } \\
\text { Preoperative hospital } \\
\text { stay (mean)(day) }\end{array}$ & $\begin{array}{l}5 \\
4.5\end{array}$ & $\begin{array}{l}4 \\
4.1\end{array}$ \\
\hline
\end{tabular}


Table (2): Intraoperative Parameters.

\begin{tabular}{|l|ll|}
\hline & PG $(\mathbf{N}=\mathbf{1 8})$ & PJ $(\mathbf{N}=\mathbf{1 5})$ \\
\hline $\begin{array}{l}\text { Type of resection } \\
\text { pylorus preserving } \\
\text { classic }\end{array}$ & 4 & 3 \\
$\begin{array}{l}\text { Blood loss (ml) } \\
\text { Blood transfusion } \\
\text { (number of units) }\end{array}$ & 14 & 12 \\
$\begin{array}{l}\text { Operative time (hr) } \\
\text { Pancreas texture }\end{array}$ & 1.27 & 990 \\
$\quad \begin{array}{l}\text { Hard/ Firm } \\
\text { Soft }\end{array}$ & 13 & 1.12 \\
Size of pancreatic duct & 5 & 5.1 \\
•3mm & 11 & 12 \\
$<3 \mathrm{~mm}$ & 7 & 3 \\
\hline
\end{tabular}

Table (3): Histopathologic Specimen Examination.

\begin{tabular}{|l|cc|}
\hline & PG $(\mathbf{N}=\mathbf{1 8})$ & PJ $(\mathbf{N}=\mathbf{1 5})$ \\
\hline Periampullary carcinoma & & \\
Pancreatic & 8 & 7 \\
Ampullary & 5 & 4 \\
Duodenal & 2 & 3 \\
Bile duct & 2 & 1 \\
Pancreatitis & 1 & 0 \\
\hline
\end{tabular}

Six patients developed pancreatic fistula, 3 in PG group and 3 in PJ group. These patients were given somatostatin, proton pump inhibitors, 3rd generation cephalosporins, metronidazole and total parentral nutrition. 5 fistulas closed spontaneously. Figure(3) shows a comparison between fistulas occurring in both groups in term of mean time in days for spontaneous closure. The 6th patient with pancreatic fistula rapidly deteriorated after 12 days of the operation. Massive intraperitoneal hemorrhage occurred in this patient. Urgent exploration was done and revealed splenic artery erosion; artery ligation, splenectomy, and drainage were performed but the patient did not withstand the hypovolemic shock and died immediately after surgery.

Pancreatic leak and fistula were compared to the type of management of the pancreatic remnant whether PG or PJ, to pancreas texture, size of pancreatic duct, age, estimated blood loss and operative time. 


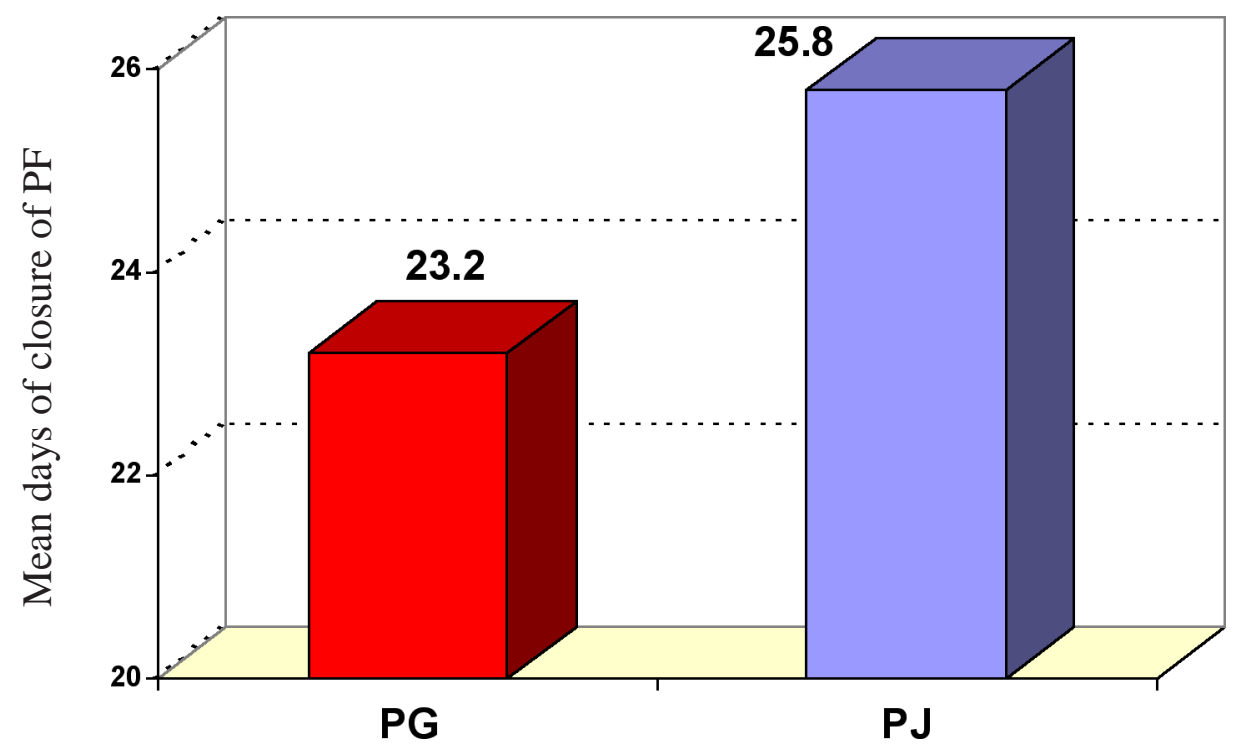

Figure (4): Mean days of closure of PF complicating PG and PJ.

According to our results as shown in Table(4), the rate of the pancreatic leak and fistula is not influenced by the type of anastomosis whether PG or PJ, however, other factors as pancreas texture, pancreatic duct diameter, operative time, estimated blood loss, and patient's age have a more influencing role.

Table (4): Role of type of pancreatic anastomosis, pancreas texture, pancreatic duct size, operative time, estimated intraoperative blood loss, and patient's age in the development of pancreatic leak.

\begin{tabular}{|l|c|c|}
\hline Variables & Pancreatic leak (n) & Pancreatic leak (\%) \\
\hline PG $(\mathrm{n}=18)$ & 4 & 22.2 \\
PJ $(\mathrm{n}=15)$ & 4 & 26.6 \\
Hard pancreas $(\mathrm{n}=25)$ & 5 & 20 \\
Soft pancreas $(\mathrm{n}=8)$ & 3 & 37.5 \\
Pancreatic duct $\cdot 3 \mathrm{~mm}(\mathrm{n}=21)$ & 4 & 23.8 \\
Pancreatic duct $<3 \mathrm{~mm}(\mathrm{n}=12)$ & 4 & 25 \\
Operative time $>7 \mathrm{hr}(\mathrm{n}=12)$ & 4 & 33.3 \\
Operative time $<7 \mathrm{hr}(\mathrm{n}=21)$ & 4 & 19 \\
Estimated blood loss $>1.7 \mathrm{~L}(\mathrm{n}=8)$ & 3 & 37.5 \\
Estimated blood loss $<1.7 \mathrm{~L}(\mathrm{n}=25)$ & 5 & 20 \\
Age $>65(\mathrm{n}=7)$ & 2 & 28.5 \\
Age $<65(\mathrm{n}=26)$ & 6 & 23 \\
\hline
\end{tabular}


Concerning the 12 cases with pancreatic duct $<3 \mathrm{~mm}$ diagnosed intraoperatively, 7 had undergone PG, 4 of them had a hard pancreas and 5 had undergone PJ, 3 of them had a hard pancreas. 4 cases of leak were recorded among these 12 patients, 3 from the PJ and 1 from PG group. Hence, the type of pancreatic anastomosis in case of small duct had markedly affected the rate of leakage.

Table(5) shows the extra-abdominal and abdominal complications compared to the development of pancreatic leak and fistula and to the type of anastomosis.

The overall mortality which was defined as death occurring within 30 days of the operation was $5 / 33(15 \%)$. Two patients died due to pancreatic leak with abdominal collection; one from each group at the 6th and 9th postoperative day. The 3 rd patient died at the 12 th postoperative day due to splenic artery erosion and intraperitoneal bleeding complicating pancreatic fistula. Another patient died after 7 days of surgery. He had no pancreatic leak, but he developed massive pulmonary embolism. The 5th patient died suddenly at home 28 days after surgery. He had been discharged from the hospital after 9 days in a fine condition. The cause of the death is unknown, but massive myocardial infarction is probably the cause as the patient had a history of coronary artery disease.

Table (5): Extra-abdominal and abdominal complications compared to the development of pancreatic leak/fistula and to the type of anastomosis.

\begin{tabular}{|l|c|c|c|c|}
\hline Complications & No leak & Leak / Fistula & PG & PJ \\
\hline Stroke & 0 & 1 & 1 & 0 \\
Pneumonia & 1 & 2 & 1 & 2 \\
Pulmonary atelectasis & 1 & 3 & 1 & 3 \\
Pulmonary embolism & 1 & 0 & 1 & 0 \\
Myocardial infarction & 1 & 0 & 0 & 1 \\
DVT & 0 & 2 & 1 & 1 \\
Stress ulcer & 0 & 2 & 0 & 2 \\
urinary tract infection & 2 & 3 & 1 & 4 \\
Bile leak & 0 & 1 & 0 & 1 \\
Gastrojejunostomy/ Duodenojejunostomy leak & 0 & 0 & 0 & 0 \\
Pancreatitis & 0 & 3 & 1 & 2 \\
Abdominal collection & 0 & 3 & 1 & 2 \\
Abdominal abscess & 0 & 2 & 1 & 1 \\
Wound infection & 2 & 7 & 3 & 6 \\
Delayed gastric emptying & 1 & 2 & 2 & 1 \\
Intraperitoneal bleeding & 0 & 1 & 0 & 1 \\
Percutaneous drainage & 0 & 3 & 1 & 2 \\
Relaparotomy & 0 & 2 & 1 & 1 \\
Post operative hospital stay (mean days) & 8.4 & 19.7 & 14.1 & 15.2 \\
Mortality & 2 & 3 & 2 & 3 \\
\hline
\end{tabular}

\section{Discussion:}

The pancreatic-enteric anastomosis has been referred to as the "Achilles heal" of PD because it has been associated with a measurable risk of leakage or failure of healing, resulting in pancreatic fistula. ${ }^{6}$ Because leakage at the site of the pancreatic-gastrointestinal anastomosis produces morbidity and mortality following PD, several techniques aimed at prevention of pancreatic anastomosis leakage have been extensively studied, ${ }^{7-9}$ but none of these techniques was unanimously accepted to be safer. $^{5}$ 
The most common techniques for management of the pancreatic remnant after PD involve a pancreatic-enteric anastomosis either PG or PJ.

Many theories have been put forward to support using PG over PJ. ${ }^{10}$ Pancreatic enzymes are inactivated by the acidic gastric fluid. In addition, the stomach does not contain enterokinase, which is required for the conversion of trypsinogen to trypsin and subsequent activation of other proteolytic enzymes. A lack of enzymatic activation may help prevent autodigestion of the anastomosis. The proximity of the pancreas to the posterior wall of the stomach allows for potentially less tension on the anastomosis.

The excellent blood supply to the stomach wall is favorable to anastomosis healing and the thickness of the stomach wall holds sutures well. Nasogastric decompression provides for continuous emptying of the stomach and, therefore less tension on the pancreaticogastrostomy anastomosis, a benefit not possible with a pancreaticojejunal anastomosis. ${ }^{11} \mathrm{PG}$ avoids a long jejunal limb between the pancreatic and biliary anastomosis where biliary and pancreatic secretions can collect and cause increased pressure resulting in tension at both the pancreatic and biliary anastomoses. ${ }^{12}$

Because of the above theories pancreatic gastrostomy has gained favor as a potential means of reducing the incidence of pancreatic fistula after PD. 13-16

A meta-analysis of 15 years of literature on pancreatic fistula after PD was done by Bartoli et al. ${ }^{17}$ They compared PG versus PJ anastomosis and they found PG to be associated with lower morbidity and mortality. This is consistent with a previous report on 160 consecutive patients by Fabre et al ${ }^{18}$ that suggested that $\mathrm{PG}$ is a safe procedure with low mortality and morbidity.

In group of 86 patients treated by the same surgeon, Kim et a ${ }^{19}$ found a significant better early outcome using PG compared with PJ.

Another study carried by Schmidt et al ${ }^{20}$ showed that PJ was significantly associated with PF. These data were supported by Arnaud et $\mathrm{al}^{21}$ in their study where they confirmed that PG is associated with lower leak rather than
PJ and therefore deserves more widespread use. In another non randomized study by Takano et al ${ }^{22}$ similar to a large (441) patients but retrospective study analyzed by Schlitt, ${ }^{23}$ PG was found to be significantly safer than PJ, particularly regarding the incidence of pancreatic fistula.

Oussoultzoglow et $\mathrm{al}^{5}$ found no difference in mortality, but a significant reduction in the rate of pancreatic fistula and the duration of hospital stay in favor of $\mathrm{PG}$ reconstructions in 250 patients analyzed retrospectively. All the above mentioned studies were in contrast to the results in our study.

In contrast to the above mentioned results, the rate of pancreatic leak / fistula, our study endpoint was nearly similar in a comparison of PG and PJ. The results are in accordance with the results reported by Bassi et al, ${ }^{24}$ which did not reveal any significant differences between PG and PJ in the incidence of pancreatic leak / fistula. Our results are also consistent with a large randomized study comparing PG and PJ at the Johns Hopkins Hospital that showed no difference in the rate of fistula following the two procedures. ${ }^{25}$

Although the overall rate of pancreatic leak in our study did not differ in both groups, the overall rate of complications was higher in PJ group. The same finding was obtained by Bassi et al. ${ }^{24}$

A registered difference between both groups in our study is that fistula following a PG anastomotic leakage took a shorter time to close than those following PJ breakdown and hence, the duration of hospital stay was higher in complicated PJ group. This is consistent with the results obtained by Aranha et al. ${ }^{12}$

Another important finding in our study is that the rate of pancreatic leak in case of small pancreatic duct was higher after pancreaticojejunostomy rather than pancreaticogastrostomy.

There exist certain important factors that directly affect the rate of pancreatic leak, such as surgeon's experience, pancreatic texture, the size of the pancreatic duct, patient's age, estimated blood loss and operative time. Several studies support our findings; many trials have found that the risk of the post- operative pancreatic fluid was significantly high in the 
presence of soft texture pancreas. ${ }^{26-28}$ Other investigators have associated a small pancreatic duct as a contributing factor to PF formation. 8,29

\section{Conclusion:}

On the basis of the results of our prospective randomized trial, compared $\mathrm{PJ}$ and $\mathrm{PG}$ following PD does not significantly change the risk of pancreatic leak /fistula. However, the rate of leakage in case of small pancreatic duct is lower in PG than in PJ. The overall complications are also higher in PJ than in PG. Therefore, we found PG to be safer than PJ as method of pancreatic reconstruction after PD, especially when a small pancreatic duct is encountered. We also conclude that other factors rather than the type of anastomosis affect directly the outcome such as surgeon's experience and technical precision in construction of the pancreatic anastomosis, the consistency of the pancreatic parenchyma and the size of the pancreatic duct. Other secondary factors that may play a role are the patient's age, estimated blood loss, and operative time.

\section{References:}

1- Shrikhande SV, Barreto G, Shukla PJ: Pancreatic fistula after pancreaticoduodenectomy: The impact of a standardized technique of pancreaticojejunostomy. Langenbecks Arch Surg 2008; 393: 87-91.

2- Goulet RJ Jr, Curie H, Loehrer PJ, Lillemoe KD, Madura JA CA, Baumgardner JA, Cummings OW, Jacobson LE, Broadie TA, Canal DF, EA, Cardenes Schmidt CM, Powell ES, Yiannoutsos CT, Howard TJ, Wi ebke EA, Wiesenauer: Pancreaticoduodenectomy: A 20-year experience in 516 patients. Arch Surg 2004; 139: 718-725.

3- Balcom JH 4th, Rattner DW, Warshaw AL, Chang Y, Fernandez-del Castilo C: Tenyear experience with 733 pancreatic resections: Changing indications, older patients and decreasing length of hospitalization. Arch Surg 2001; 136: 391 398.

4- Trede M, Schwall G: The complications of pancreatectomy. Ann Surg 1988; 207: 3947.
5- Oussoultzoglou E, Bachellier P, Bigourdan J, Weber JC, Nakano H, Jaeck D: Pancreaticogastrostomy decreased relaparotomy caused by pancreatic fistula after pancreaticoduodenectomy compared with pancreaticojejunostomy. Arch Surg 2004; 139: 327-335.

6- Berger A, Howard T, Kennedy E, Sauter P, Bower-Cherry M, Dutkevitch S, Hyslop T, Schmidt C M, Rosato EL, Lavu H, Nakeeb A, Pitt Henry A, Lillemoe KD, Yeo CJ: Does type of pancreaticojejunostomy after pancreaticoduodenectomy decrease rate of pancreatic fistula? A randomized, prospective, dual-institution trial. $J \mathrm{Am}$ Coll Surg 2009; 208(5): 738-747.

7- Roder JD, Stein HJ, Bottcher KA, Busch R, Claus-Dieter H, Steinert JR. Stented versus nonstented pancreaticojejunostomy after pancreaticoduodenectomy: A prospective study. Ann Surg 1999; 1: 4148.

8- Marcus SG, Cohen H, Ranson JHC: Optimal management of the pancreatic remnant after pancreaticoduodenectomy. Ann Surg 1995; 221: 635-648.

9- Papadimitriou JD, Fotopoulos AC, Smyrniotis B, Prahalias AA, Kostopanagiotou G, Papadimitriou LJ: Subtotal pancreaticoduodenectomy: Use of a defunctionalized loop for pancreatic stump drainage. Arch Surg 1999; 134: 135 139.

10-Pikarsky AJ, Muggia-Sullam M, Eid A, lyass S, Bloom AI, Durst AL: A retrospective analysis of 28 patients. Arch Surg 1997; 132: 296-299.

11-Aranha G, Aaron J, Shoup M: Critical analysis of a large series of pancreaticog a s t r o s t o m y a f t e r pancreaticoduodenectomy. Arch Surg 2006; 141: 574-580.

12-Aranha GV, Hodul Pamela, Golts E, Oh D, Pickelman J: A Comparison of pancreaticogastrostomy and pancreaticojejunostomy following pancreaticoduodenostomy. J Gastrointest Surg 2003; 7(5): 672-682.

13-Delcore R, Thomas JH, Pierce GE, Hermreck AS: Pancreatogastrostomy: A 
safe drainage procedure after pancreatoduodenectomy. Surgery 1990; 108: 641-643.

14-Kapur BML: Pancreaticogastrostomy in pancreaticoduodenal resection for ampullary carcinoma: Experience with thirty-one cases. Surgery 1986; 100: 489493.

15-Mason GR, Freeark RJ: Current experience with pancreaticogastrostomy. Am J Surg 1995; 169: 217-219.

16-Icard P, Dubois F: Pancreaticogastrostomy following pancreaticoduodenectomy. Ann Surg 1988; 207: 253-256.

17-Bartoli FG, Arnone GB, Ravera G, Bachi $\mathrm{V}$ : Pancreatic fistula and relative mortality in malignant disease after pancreaticoduodenectomy: Review and statistical meta-analysis regarding 15 years of literature. Anticancer Research 1991; 11:1831-1848.

18-Fabre JM, Arnaud JP, Navarro F, Bergamaschi R, Cervi C, Marrel E, Domergue J: Results of pancreatogastrostomy after pancreaticoduodenectomy in 160 consecutive patients. Br J Surg 1998; 85: 751-754.

19-Kim SW, Youk EG, Park YH: Comparison of pancreaticogastrostomy and pancreaticojejunostomy after pancreaticoduodenectomy performed by one surgeon. World J Surg 1997; 21: 640643.

20-Schmidt C, Choi J, Powel E, Yiannoutsos C, Zyromski N, Nakeeb A, Pitt H, Wiebke E, Madura J, Lillemoe K: Pancreatic fistula following pancreatico-duodenectomy: Clinical predictors and patient outcomes. HPB Surg 2009; 1-8.

21-Arnaud J, Tuech J, Cervi C, Bergamaschi R: Pancreaticogastrostomy compared with pancreaticojejunostomy after pancreaticoduodenectomy. Eur J Surg 1999; 165: 357-362.

22-Takano S, Ito Y, Watanabe Y, YokoyamN, Kubota N, Iwai S: Pancreaticojejunostomy versus pancreaticogastrostomy in reconstruction following pancreaticoduodenectomy. Br J Surg 2000; 87: 423-427.

23-Schlitt HJ, Schmidt U, Simunec D, Jager M, Aselmann H, Neipp M, Piso P: Morbidity and mortality associated with pancreatogastrostomy and pancreatojejunostomy following partial pancreatoduodenectomy. Br J Surg 2002; 89: 1245-1251.

24-Bassi C, Falconi M, Molinari E, Salvia R, Butturini G, Sartori N, Mantovani W, Pederzoli P: Reconstruction by pancreaticojejunostomy versus pancreaticogastrostomy following pancreatectomy: Results of a comparative study. Ann Surg 2005; 242(6): 767-771.

25-Yeo CJ, Cameron JL, Sohn TA, Lillemoe KD, Pitt HA, Talamini MA, Hruban RH, Ord SE, Sauter PK, Coleman J, Zahurak ML, Grochow LB, Arbrams RA: Six hundred fifty consecutive pancreaticoduodenectomies in the 1990's: Pathology, complications and outcomes. Ann Surg 1997; 226: 248-260.

26-Baumel H, Huguier M, Manderscheid JC: Results of resection for cancer of the exocrine pancreas: A study from the French Association of Surgery. Br J Surg 1994; 81:102-107.

27-Yeo CJ, Cameron JL, Maher MM, Sauter PK, Zahurak ML, Mark AT, Lillemoe KD, Pitt HA: A prospective randomized trial of pancreaticogastrostomy versus pancreaticojejunostomy after pancreaticoduodenectomy. Ann Surg 1995; 222(4): 580-592.

28-Lin JW, Eng M, Cameron JL, Yeo CJ, Raill TS, Lillemoe KD: Risk factors and outcomes in post-pancreaticoduodenectomy pancreaticocutaneous fistula. $J$ Gastrointest Surg 2004; 8: 951-959.

29-Hamanaka Y, Nishihara K, Hamasaki T, Kawabata A, Yamamoto S, Tsurumi M, Ueno T, Suzuki T: Pancreatic juice output after pancreaticoduodenectomy in relation to pancreatic consistency, duct size, and leakage. Surg 1996; 119(3): 281-287. 